\title{
Diccionario y estandarización lingüística en Hispanoamérica: la visión de Ramón Sotomayor Valdés (1866)
}

\author{
Dictionary and linguistic standardization in Spanish America: the view of Ramón \\ Sotomayor Valdés (1866)
}

\begin{abstract}
Darío Rojas
Universidad de Chile, Departamento de Lingüística. Av. Capitán Ignacio Carrera Pinto 1025, Piso 3, Ñuñoa, Santiago, Chile. C. P. 7800284. Correo electrónico: darioroj@u.uchile.cl
\end{abstract}

En el presente artículo, en el marco de la historiografía lingüística, describimos las ideas del político conservador, historiador y periodista chileno Ramón Sotomayor Valdés (18301903) acerca del papel del diccionario en la estandarización lingüística hispanoamericana. Nos basamos en su discurso de incorporación a la Facultad de Filosofía y Humanidades de la Universidad de Chile, publicado en 1866, casi una década antes que el primer diccionario de provincialismos chilenos. Mostramos que la visión de Sotomayor refleja fielmente la ideología lingüística monoglósica, homogeneizante y propeninsular de los unionistas, tales como Andrés Bello, influenciada fuertemente por el modelo racionalista de la estandarización. Además, señalamos que su ideario lingüístico tiene conexión muy estrecha con su ideología política.

Palabras clave: historiografía lingüística, lexicografía, metalexicografía, ideologías lingüísticas, actitudes lingüísticas.

In this paper, framed within linguistic historiography, we describe the ideas of Chilean conservative politician, historian and journalist Ramón Sotomayor Valdés (1830-1903) about the role of the dictionary in language standardization in Latin America. Our source is Sotomayor's admission speech read in the Faculty of Philosophy and Humanities of the University of Chile in 1866. From this year, near a decade would pass until the publication of the first dictionary of Chilean provincialisms. We show that Sotomayor's views accurately reflect the unionist language ideology, held by intellectuals such as Andrés Bello. This language ideology is monoglossic, homogenizing and pro-Castilian, and is strongly influenced by the rationalist model of standardization. Furthermore, we point out that Sotomayor's language ideology has a very close link with his political ideas.

Key words: linguistic historiography, lexicography, metalexicography, language ideologies, language attitudes.

Financiado por Programa U-APOYA Línea 2: Concurso de Proyectos de Investigación en Ciencias Sociales, Humanidades, Artes y Educación VID 2011; código SOC U-SOC-11/12; Universidad de Chile. 


\section{INTRODUCCIÓN}

El siglo XIX atestiguó una intensa reflexión sobre el lenguaje en Hispanoamérica. El problema de la unidad de la lengua, suscitado por los procesos independentistas, fue uno de los más discutidos por los intelectuales de la época (Del Valle y GabrielStheeman 2004), entre los que destacan figuras fundacionales de la lingüística hispanoamericana como Andrés Bello y Rufino José Cuervo. En términos generales, se trataba de un problema de identidad lingüística: ¿qué hacer con la lengua heredada de los antiguos dominadores españoles? Entre las diversas posturas surgidas (Lara 2009: 177-179), salió triunfante, en la mayor parte de Hispanoamérica, la de los unionistas (Quesada 2002) como Andrés Bello, quien pensaba que lo más beneficioso para las nuevas repúblicas era mantener el español "en su posible pureza, como un medio providencial de comunicación y un vínculo de fraternidad entre las varias naciones de origen español derramadas sobre los dos continentes” (Bello 1847: x-xi).

La reflexión decimonónica sobre la lengua española en Hispanoamérica tuvo como marco una serie de procesos de estandarización lingüística circunstanciada. En Chile, este proceso puede darse por iniciado durante la primera mitad del siglo (Matus, Dargham y Samaniego 1992). En términos del modelo de Haugen (1966), el siglo XIX hispanoamericano tuvo relevancia para los procesos de selección y codificación de la lengua española. Los textos metalingüísticos hispanoamericanos, tales como los diccionarios de provincialismos (Haensch 2000), se ocupaban principalmente de la selección de ciertos rasgos lingüísticos propios de las variedades americanas que, de acuerdo con ciertos méritos, podían ser considerados dignos de formar parte de la norma estándar hispánica; es decir, actuaban como una especie de "colador" normativo (Rojas 2010). De ser considerados aceptables, esto se veía reflejado, idealmente, en la incorporación de dichos rasgos a obras como el D iccionario de la lengua castellana o la Gramática de la Real Academia Española, que eran los textos codificadores por excelencia.

Además de los procesos que afectan al código, sin embargo, también es necesario considerar los aspectos lingüístico-ideológicos de la estandarización, pues “el poder, el valor y la atracción del lenguaje estándar es el resultado de complejos procesos de formación ideológica”1 (Deumert y Vandenbussche 2003: 461; trad. del editor). En otras palabras, la lengua estándar cumple su función no solo por sus características lingüísticas, sino también por el valor simbólico que la comunidad le asigna en relación con otros órdenes de la vida social.

La reflexión metalingüística de la época en cuestión no muestra, en absoluto, una corriente de opinión uniforme. Se puede apreciar, más bien, un debate lingüístico ideológico (Blommaert 1999), o una negociación explícita de normas (Andersen 2009), en que distintas posturas acerca de la relación entre lenguaje y nación, educación, política, literatura, etc., eran defendidas o rebatidas en diversos espacios discursivos públicos (periódicos, libros, revistas, etc.) y sobre la base de diversos argumentos. Esto se puede apreciar, por ejemplo, en el acalorado debate acerca de temas lingüísticos que sostuvieron algunos intelectuales avecindados en Chile, conocido como "la controversia filológica de 1842" (Pinilla 1945). Lo interesante,

En el original: "the power, value and attraction of standard language is a result of complex processes of ideology formation". 
desde el punto de vista de la estandarización lingüística, es que es precisamente en este tipo de debates donde las ideologías lingüísticas se articulan y refuerzan (Blommaert 1999: 1). De esta manera, la producción metalingüística del s. XIX hispanoamericano constituye un magnífico observatorio de las ideas, creencias y concepciones acerca del lenguaje, es decir, de las ideologías lingüísticas (Kroskrity 2010) que tuvieron un papel fundamental en el proceso de estandarización de las variedades americanas.

En este artículo nos proponemos abordar un aspecto muy concreto de la ideología lingüística del s. Xix hispanoamericano: el rol que se pensaba que debía jugar el diccionario en los procesos de estandarización. El género lexicográfico fue uno de los principales instrumentos "glotopolíticos” de los procesos de estandarización hispanoamericanos (Lauria 2011). Sin embargo, no abundan los estudios sobre las ideas específicas que sirvieron de fundamento para este rol, según fueron expresadas por los propios agentes que participaron en la estandarización. Nuestra contribución se circunscribe a un ejemplo de los “textos programáticos en los que los 'estandarizadores' esbozan y defienden sus propuestas"'2 (Deumert y Vandenbussche 2003: 461; trad. del editor): el discurso que Ramón Sotomayor Valdés (1830-1903) leyó con ocasión de su incorporación a la Facultad de Filosofía y Humanidades de la Universidad de Chile en 1866 y que fue publicado ese mismo año en los Anales de la institución (Sotomayor 1866). Este discurso es especialmente interesante porque fue publicado casi una década antes que el primer diccionario de provincialismos chilenos (elaborado además por uno de sus amigos y correligionarios políticos: Rodríguez 1979 [1875]) y, por lo tanto, puede considerarse que representa fielmente el clima de opinión que da origen a la lexicografía precientífica chilena (Matus 1994). Además, es el más antiguo de los estudios metalexicográficos chilenos, según los datos de que se dispone hasta ahora (Rabanales 2004-2005: 159), lo cual le otorga un interés adicional por su carácter seminal.

En la sección siguiente esbozaremos un perfil de las ideas políticas de Sotomayor, en cuyo marco se inserta su pensamiento lingüístico. Luego intentaremos sistematizar el contenido del discurso de Sotomayor, e inmediatamente a continuación lo analizaremos en términos de la ideología lingüística que le subyace. Cerramos el estudio resumiendo nuestras principales conclusiones.

\section{EL AUTOR Y SU IDEARIO POLÍTICO ${ }^{3}$}

Ramón Sotomayor Valdés (Santiago, Chile, 1830-1903) fue "uno de los más notables representantes de la intelectualidad conservadora en la segunda mitad del siglo XIX” (Brahm 1992: 7). Tuvo como principales ocupaciones el periodismo, la historia y la política, aunque inicialmente tuvo formación de jurista en la Universidad de Chile. Entre las tareas relacionadas con el primero de estos ámbitos, escribió frecuentemente en EI Mensajero, El Conservador, La República, La Actualidad, La Unión, El Porvenir, El Diario y El Ferrocarril, dentro de una amplia gama de periódicos de línea editorial conservadora. Manifestó su afición por las letras

En el original: "programmatic texts in which the 'standardizers' outline and defend their proposals".

Los datos biográficos del autor fueron obtenidos de los sitios web Memoria Chilena e Historia Política Legislativa del Congreso Nacional de Chile, así como de Araneda (1930), Brahm (1992) y Galdames (1930). 
principalmente a través del género histórico (escribió una Historia de Chile, desde 1831 hasta 1871), y fue nombrado miembro de la Facultad de Filosofía y Humanidades de la Universidad de Chile (1866) y de la Academia Chilena de la Lengua (1885) (y, poco después, como correspondiente de la Real Academia Española). Por añadidura, fue profesor de Historia Literaria en el Instituto Nacional. En cuanto a su vida política, fue miembro del Partido Conservador, a pesar de que durante sus estudios en el Instituto Nacional tuvo profesores de ideas liberales, como Ramón Briceño y José Victorino Lastarria. Su perfil conservador, de tinte pelucón, "se vio reflejado en su defensa decidida de la herencia hispánica y su transformación en un fervoroso devoto del catolicismo” (Memoria Chilena, s. f.), además de la alta estimación en que tuvo el autoritarismo y su reivindicación de las ideas de Diego Portales. Ejerció como ministro del Gobierno chileno en México (1863) y Bolivia (1867). Fue elegido diputado por Rancagua (1864-1867) e Itata (1867-1870) y fue nombrado oficial mayor del ministerio de Hacienda (1873). Enseñó Economía Política en la Universidad de Chile y en la etapa tardía de su vida fue gerente del Banco de Crédito Unido de Santiago (1888-1889).

De acuerdo con la tipología de autores de comentarios metalingüísticos de Paveau (2011), Sotomayor puede contarse entre los "non-linguist academics" o "académicos no lingüistas" por su condición de individuo especialista en alguna disciplina académica pero sin formación especializada en lingüística. Por lo demás, nuestro autor escribe en un momento en que la lingüística moderna, en cuanto ciencia empírica y descriptiva, aún no existía. En la tipología de Paveau, que comprende un continuo ordenado de mayor a menor posesión de conocimiento lingüístico, y que va desde lingüistas profesionales hasta los hablantes comunes, los académicos no lingüistas se encuentra solo por debajo de los lingüistas profesionales en cuanto a grado de especialización. Andrés Bello podría ser un ejemplo de lingüista profesional de la época, aunque su perfil dista en varios aspectos del de un lingüista moderno. A diferencia de Bello, Sotomayor no dedicó una parte importante de sus trabajos al tema lingüístico: el trabajo que analizamos en este artículo es el único ejemplo de su reflexión metalingüística del que disponemos. Al comenzar su discurso, a manera de captatio benevolentiae, el mismo Sotomayor expresa estar consciente de que él no es una autoridad en la materia y en el desarrollo del mismo constantemente menciona a Bello como verdadera autoridad. En conclusión, Sotomayor opina desde el punto de vista de un no especialista, un lego, podríamos decir, como la mayoría de quienes escribieron acerca del lenguaje en el Chile decimonónico, pero su opinión adquiere autoridad gracias a su competencia en áreas afines (periodismo, historia, política). Es su prestigio social y político, precisamente, lo que hace pensar que sus ideas pudieron haber sido influyentes incluso entre quienes desempeñaban un rol más especializado; según plantean Wilton y Wochele, "es una falacia creer que porque un punto de vista es secular, es automáticamente menos influyente que las afirmaciones respaldadas por la credibilidad científica"4 (2011: 58; trad. del editor). Algunas décadas después de su muerte, Araneda (1930: 666-667) comenta lo influyente y prestigioso que Sotomayor fue en la vida intelectual chilena de la segunda mitad del s. XIX. Da a entender, igualmente, que el discurso de Sotomayor inspiró el trabajo lexicográfico

En el original: "it is a fallacy to think that because a view is lay it is automatically less influential than statements backed by the credibility of science". 
que la Academia Chilena de la Lengua se propondría acometer bajo el secretariado de Samuel Lillo (de 1929 a 1937). El mismo Lillo, al terminar la década de 1920, señala entre las tareas próximas de la Academia Chilena y sus homólogas americanas "la preparación de un Léxico Hispano Americano que se agregaría como un suplemento al Diccionario de la Real Academia” (1929: 550).

Brahm (1992) ofrece una acabada descripción del ideario político de Sotomayor, que permite contextualizar adecuadamente su ideología lingüística en torno al diccionario. En general, nuestro autor es un fiel representante "del peluconismo o conservadurismo monttvarista de la década de los cincuenta [del s. XIx]” (Brahm 1992: 8). Ponía énfasis en la importancia del progreso, entendido este, en términos positivistas y materialistas, como el incremento del bienestar material. Creía, sin embargo, en un progreso sin riesgos, sometido al orden, que avanzara de forma lenta pero segura. Sotomayor reacciona contra el racionalismo idealista típico de la época del liberalismo romántico; reniega de la teoría y de los sistemas que “operan sin consideración de las diversidades materiales, de las concretas y particulares características de las distintas sociedades” (Brahm 1992: 9). Los conservadores chilenos de la época "querían que las políticas se adecuaran a las realidades nacionales, que se probaran por la experiencia y, en fin, se hacía gala de un cierto escepticismo frente a las ingenuas soluciones de los extremistas liberales” (Brahm 1992: 10). Entre las manifestaciones de esto se encuentra un fuerte escepticismo frente al principio de soberanía popular, oponiendo a él "un gobierno de los 'sabios', de los 'científicos', única forma de controlar 'el desorden íntimo que inevitablemente engendraba”’ (Brahm 1992: 11). Sotomayor pensaba que la soberanía popular tenía sus límites demarcados por elementos sociales (el aristócrata no puede ser pasado a llevar por el pueblo), racionales (la participación política debía limitarse a los sujetos de cierto nivel cultural), legalistas (de acuerdo con las ideas de Portales) y morales (catolicismo) (Brahm 1992: 26). Durante los años en que Sotomayor ejerce su carrera política en el extranjero, se forma una opinión muy negativa de la situación política del resto de Hispanoamérica en comparación con Chile, y llega a pensar que Chile debe su excepcional estabilidad política a la dureza del régimen de Diego Portales y a la Constitución Política de 1833. Gracias a esos antecedentes, cree Sotomayor, Chile podía ser considerado en ese momento "modelo de Estado emprendedor entre los países hispanoamericanos hasta las décadas centrales del siglo XIX” (Brahm 1992: 25). Aunque en su temprana juventud Sotomayor criticó fuertemente al presidente Manuel Montt por su autoritarismo, con el paso de los años la idea de un presidente fuerte y de amplios poderes pasa a ocupar un lugar muy importante en su ideología política, acentuándose así su conservadurismo.

\section{Contenido del texto}

Sotomayor declara su cometido al comenzar su discurso: ${ }^{5}$

Es mi propósito fijar vuestra atencion en la necesidad i conveniencia de formar, por medio de un cuerpo literario propio de la América latina, el Diccionario de nuestra lengua, no con el objeto de desviarla, que desviándose va, de la buena i majestuosa índole que le imprimiera la literatura española de otros siglos, sino precisamente para

En todas las citas de Sotomayor (1866), respetamos la ortografía original del texto. 
evitar la dejeneracion del idioma castellano en las diversas secciones de la América ántes española (Sotomayor 1866: 665).

Introducir esta autoridad es necesario con especial urgencia en Hispanoamérica, pues varios factores contribuyen a la "dejeneracion del idioma”:

a) La idea de desespañolizar América e introducir como referente otros idioma, como el francés (con esto alude a la propuesta de Luciano Abeille en Argentina). De esta desespañolización lingüística derivan la importación masiva de léxico y el calco del estilo literario extranjero. Sotomayor declara sentir como propios a los escritores castellanos, con tanto o más derecho que un español: "nuestro Lope, nuestro Cervantes”, etc. “¿No hemos heredado su idioma que es, por decirlo así, la constitucion física de las ideas i que establece entre los hombres, relaciones fisiolójicas, análogas a los lazos de familia?" (Sotomayor 666). Cree que este sentimiento podría ser percibido por muchos americanos como una falta de lealtad, pero él no está de acuerdo. Siente que desespañolizar América sería más una pérdida que una real mejora, "una venganza que parece un suicidio” (Sotomayor 667), pues con la erradicación de lo español se perderían "dotes de antigüedad, doctrina, riqueza, propiedad, finura, etc.” (Sotomayor 667) que contribuyen a la grandeza del idioma.

b) La inmigración de extranjeros que, pese a contribuir al rápido progreso de Chile, introducen una fuente de disrupción de "la unidad i la fisonomía clásica de nuestra lengua, inundándola de elementos que no ha menester i que, con conservar su forma estrambótica, la van desfigurando caprichosamente" (Sotomayor 667). Sotomayor vincula esta invasión con el hecho de que lo extranjero, en general, es prestigioso en Chile, y con que la formación intelectual se hace sobre la base de textos extranjeros malamente traducidos al español. Para él, lo importante, en cualquier caso, es someter el enorme cauce de innovaciones motivadas por el flujo inmigratorio "al curso indicado por las condiciones i la índole de nuestro idioma, en vez de dejarlo a la merced i capricho del acaso” (Sotomayor 668).

c) La mala calidad lingüística de la literatura periodística, motivada por la urgencia de producir grandes cantidades de textos con un ritmo vertiginoso. Sotomayor concede que la prensa es el medio que mejor se presta para "el desenvolvimiento intelectual i social” de América, pues satisface las necesidades de las instituciones políticas, la curiosidad del vulgo y propicia la participación popular en los asuntos públicos, entre otros asuntos. Pero la urgencia señalada, asociada a la rapidez de la imprenta, hace que se escriba con poco cuidado y que haya surgido "el abuso de la palabra, el estilo profuso i superabundante” (Sotomayor 668).

Por estas razones, el autor considera necesario introducir un referente autorizado en materia de lenguaje. El modelo de lengua, para Sotomayor, es de índole literaria. Considera que para evitar la degeneración del español es necesario "tomar un vivo interes por el estudio de la literatura clásica de la España, i fijar bien con este estudio la fisonomia i carácter propios del idioma" (Sotomayor 669). Fijar el carácter propio del idioma, por otra parte, contribuye a darle lo que los sociolingüistas modernos llaman estabilidad flexible (Gallardo 1978): la capacidad de ir a la par del "progreso de las 
ideas i [...] las novedades que ocurren en la vida social” (Sotomayor 669), necesaria pues "si el lenguaje no es mas que el conjunto de signos para manifestar las ideas, preciso es que su horizonte se estienda al par del pensamiento” (Sotomayor 669).

Esta consideración entraña el problema del neologismo: “¿... hasta dónde es permitido introducir palabras nuevas en el idioma?” (Sotomayor 669). El autor considera que el neologismo es prerrogativa de los escritores y que la introducción de nuevos vocablos debe ir por la senda de la necesidad denominativa ("no se han de inventar sin necesidad”, Sotomayor 676) y el ajuste a la índole del idioma ("procuremos sacar de raices castellanas las nuevas palabras, según los procederes ordinarios de derivacion”, Sotomayor 676). La lengua castellana debe ser selectiva por haber ya alcanzado un alto grado de cultivo literario (es “un idioma ya formado"), de modo que "es bueno juntar la puerta, aunque sin condenarla" (Sotomayor 670). El autor considera, sin embargo, que muchas de las innovaciones léxicas se deben a simple desconocimiento de la tradición del idioma. El concepto de tradición articula gran parte del pensamiento lingüístico de Sotomayor:

Merece observarse que la manía de enriquecer sin necesidad una lengua con vocablos i jiros nuevos, sujetando su conformacion a los caprichos de la moda, si no rimple, dificulta grandemente la tradicion histórica y hace que un siglo no conozca a otro siglo, que un pueblo no se conozca a si mismo en el curso del tiempo sino con fatigoso trabajo; pues cuando los cambios del idioma son tan violentos, que para una jeneracion se hace inintelijible el lenguaje de otra jeneracion, el hilo de la tradicion se ha cortado, i la enseñanza del pasado se ha hecho dificil (Sotomayor 870).

Aún más, Sotomayor considera que los privilegiados que tengan la prerrogativa de introducir vocablos nuevos deberían tener conocimientos de la etimología y significados del latín, pues de este idioma el español "ha tomado no solamente el mayor caudal de sus voces, sino tambien su jiro majestuoso i libre" (Sotomayor 670). Esta afirmación posiciona la herencia latina del idioma español como una fuente de legitimidad, a lo que añade el ejemplo de los “injenios distinguidos” (Sotomayor 671) que en el s. Xv "se dieron al estudio de la antigüedad griega i latina, i probaron a sentar las bases i principios del engrandecimiento i cultura del idioma de Castilla” (Sotomayor 671).

Luego, Sotomayor continúa elaborando la idea de que la introducción de neologismos debe estar en manos de una élite. Esta vez, critica la noción de que el uso es la autoridad en materia lingüística, con el argumento de que "hai un uso que edifica i embellece, i otro que destruye i afea” (Sotomayor 671). Expresa que la preeminencia del uso, defendida por los gramáticos, no es aceptable. Los gramáticos se limitan a describir con fidelidad el estado actual de la lengua, mientras que "bien puede el uso cambiar ya no de siglo en siglo, sino de año en año" (Sotomayor 672), de manera que "no es a la gramática a la que se puede encomendar la salvacion del buen gusto, i de la herencia de lo que se llama el buen lenguaje” (Sotomayor 672). Sotomayor rechaza con vehemencia la idea de que un idioma puede estar constituido por "un conjunto de pecados que llegan a ser virtudes por el uso" (Sotomayor 672). En consecuencia, las reglas del idioma deben fijarse atendiendo al uso de las personas "doctas" o, en palabras de Andrés Bello, "la jente educada”. Por otro lado, la institucionalización de la autoridad no puede radicar en individuos, sino en "cuerpos colejiados que son el resúmen i la síntesis del progreso intelectual de nuestas sociedades” (Sotomayor 665), 
es decir, en academias que sigan el modelo de la Real Academia Española.

Postula, además, la existencia de un principio externo que regula y ordena el idioma: "sobre la simple sancion del uso, sobre la prestijiosa autoridad de los hablistas de talento prevalecen en él ciertos principios, ciertas reglas de buen gusto" (Sotomayor 673). Estos principios tienen el estatus de "limites racionales al desenvolvimiento del idioma” (Sotomayor 673). Apunta que Andrés Bello supo identificar esto al establecer sus criterios de aceptabilidad idiomática.

Su conclusión, a partir de lo desarrollado hasta este punto, es la siguiente:

I pues los maestros no han querido precisar, o no han precisado bien las reglas de este movimiento i vitalidad de nuestra lengua, i se atienen mas bien a hacerlas palpables por los ejemplos de los buenos autores, deduzco de aquí la necesidad de estudiarlos continuamente i de mirar en ellos el norte que debe hacernos distinguir el bueno del mal camino, el buen uso, del abuso del lenguaje (Sotomayor 674).

Sin embargo, Sotomayor piensa que no es suficiente con dejar claras estas reglas para que los hablantes americanos del español las interpreten a su discreción: es necesario "levantar un principio de autoridad" (Sotomayor 677), manifestado bajo la forma de un "Diccionario latino-americano para presentar en un cuerpo ordenado i fácil de consultar ese enjambre de voces que, como abejas sin colmena, vagan a la aventura i a merced del capricho de las circunstancias” (Sotomayor 677). Este diccionario se plantea como un complemento del de la Real Academia Española, que hasta ese momento, según Sotomayor, "apenas ha tomado en cuenta que el idioma de Castilla, lo es tambien de la mitad del mundo americano” (Sotomayor 677). La falta de inclusión del léxico de Hispanoamérica en el diccionario oficial también se debe, sin embargo, a que los esfuerzos anteriores en esta senda (como la inclusión de americanismos en el diccionario de Salvá) no habían sido bien ejecutados. En este punto, Sotomayor deja ver que los problemas se deben sobre todo a que quienes se han ocupado de estas tareas no han sido americanos sino extranjeros, que "ni siquiera se han rozado con nuestras sociedades" (Sotomayor 677), y que, por tanto, no se encuentran en las mejores condiciones de "fijar el sentido jenuino de muchos vocablos, i de comprobar su uso autorizado" ni de "colectar todas las voces verdaderamente usuales i dignas de figurar en el diccionario de una nacion" (Sotomayor 677).

Un modelo al momento de emprender esta tarea, para Sotomayor, es el de los estadounidenses, quienes cuentan con un diccionario propio (se refiere al diccionario de Noah Webster, probablemente). Aún más importante para nuestro autor es que la motivación de los estadounidenses no fue acentuar la divergencia lingüística, tal como él cree que los americanos no deberían pretender apartarse de la tradición hispánica, sino que tuvo raíz en "las necesidades orijinadas del desenvolvimiento de este mismo idioma [el inglés] en un pueblo a quien sus instituciones, su territorio, sus elementos sociales i su jenio han dado ya una inmensa pannsion [sic]” (Sotomayor 677).

\section{IDEOLOGÍA LINGÜÍSTICA}

Hay paralelos evidentes entre las ideas políticas de Sotomayor (presentadas en la sección 2) y su ideología lingüística: 
a) Así como en la sociedad se debe introducir un principio de autoridad, lo mismo debe hacerse en la realidad multiforme y caótica que es el lenguaje.

b) Tal como en la sociedad no todos pueden participar de la toma de decisiones importantes, en el lenguaje las decisiones deben dejarse en manos de una élite especialmente capacitada.

c) Igual como en política las teorías e ideas deben tener en cuenta el contexto específico de cada nación, la planificación lingüística debe adecuarse a las particularidades de cada país.

Estas correspondencias hacen pensar que para Sotomayor la planificación lingüística era una faceta más de la planificación social, de manera que los principios que operan en esta última también valían para la primera. El sentido de las actividades planificadoras, por otra parte, se vincula con un ideal racionalista del progreso sometido a un orden. La intervención consciente en la vida del idioma, para Sotomayor, es una necesidad social y política de las nuevas naciones hispanoamericanas en la medida en que estas se encuentran aún en estado embrionario, inicial en términos de "evolución", y en la medida en que el idioma es un instrumento importante en la construcción de las nuevas naciones.

Otra idea destacable de Sotomayor es que la propiedad del idioma es compartida entre España e Hispanoamérica. Esto se puede apreciar, por un lado, en su crítica abierta al hecho de que el diccionario "oficial" hasta ese momento haya descuidado la inclusión de voces hispanoamericanas, lo cual implica que los hispanoamericanos también pueden dar origen a vocablos y acepciones legítimas y dignas de formar parte de la lengua española estándar. Por otra parte, esta misma idea subyace a la defensa de la unidad idiomática que constantemente hace Sotomayor: lo que otorga legitimidad a los hispanoamericanos es formar parte precisamente de la misma comunidad idiomática que los españoles. Nuestro autor es abiertamente unionista (Quesada 2002) y sigue al pie de la letra muchas de las ideas de Andrés Bello sobre la conveniencia de mantener una unidad lingüística entre las distintas naciones hispanohablantes y evitar lo que Sotomayor llama la “desespañolización”, en oposición a las ideas de intelectuales como Domingo Faustino Sarmiento (Velleman 2004). El fundamento de esta unidad, y con esto llegamos a otra de las ideas clave de la ideología lingüística de Sotomayor, está en la tradición literaria, que es de donde emanan las características que hacen del español una gran lengua de cultura y una posesión muy valiosa para los hispanoamericanos.

El diccionario, en particular, se erige para Sotomayor como un instrumento de selección y codificación, como un elemento fundamental de la planificación social manifestada particularmente como un proceso de estandarización lingüística. Es interesante constatar que el diccionario hispanoamericano, para Sotomayor, es funcional tanto en lo que hoy se conoce como planificación del corpus (seleccionar usos hispanoamericanos y codificarlos) como en lo que se denomina planificación del estatus (promoción de la valoración social de esta variedad). Este último aspecto se manifiesta en que el diccionario hispanoamericano sirve de mecanismo de inclusión: sirve para hacer partícipes, a los hispanohablantes americanos, de la lengua española. Esto es patente en la abierta disputa de autoridad que Sotomayor plantea frente a España, cuando declara que el idioma, aunque de origen peninsular, es también propiedad de los americanos que lo hablan. Aún más, señala que quienes elaboren 
este diccionario deben ser hablantes nativos de la variedad geolectal en cuestión, y no extranjeros; es decir, Sotomayor quiere un diccionario hispanoamericano, hecho por los hispanoamericanos y para los hispanoamericanos. Esto, a su vez, es manifestación de su idea de que hay que considerar la especificidad de cada nación o comunidad en la toma de decisiones políticas, tal como muestra el paralelo que plantea con la situación norteamericana. Sotomayor considera que la pujante vida intelectual y social de las nuevas naciones hispanoamericanas hace imposible querer hacer permanecer a la lengua española en un estado inmóvil. La introducción de neologismos, el enriquecimiento del vocabulario, es una condición intrínseca de la vida del idioma en el contexto específico de estas nuevas naciones. Lo importante, pare él, es que el dinamismo requerido por la especificidad hispanoamericana sea encauzado de manera ordenada, a fin de que efectivamente contribuya al progreso y no se transforme en un principio de caos.

Sin embargo, es claro que para Sotomayor la participación hispanoamericana en el dominio de la lengua española debe estar reservada para una élite culta, corporeizada en una academia lingüística, que debe actuar como garante del orden. El conocimiento requerido para formar parte de esta élite emana principalmente de la interacción con la tradición literaria hispánica, de cuya observación puede deducirse un conjunto de principios que configuran el "genio" del idioma. La observación fiel de este conjunto de principios (que constituyen una reificación de la lengua), a su vez, es lo que permitirá a la élite conducir el devenir idiomático de las naciones hispanoamericanas de acuerdo con el ideal de la unidad lingüística y en conformidad con la forma ideal de la lengua española. En este aspecto, Sotomayor es derechamente antipopulista, tal como lo fue Andrés Bello (Moré 2004) y gran parte de los unionistas en Hispanoamérica, y en contraposición al populismo lingüístico de Domingo $\mathrm{F}$. Sarmiento (Velleman 2004). La misión de la élite lingüística hispanoamericana, en síntesis, es encauzar y ordenar el potencial caos subyacente al uso, basándose en diversas fuentes de erudición, para llevarlo en dirección de un modelo ideal de lengua (volveremos sobre este modelo más adelante) sometido al orden. Para lograr esta misión, según Sotomayor, la élite encontrará en un diccionario su mejor aliado.

Aunque nunca llegó a conformarse una academia hispanoamericana, tal como la imaginó Sotomayor, su idea sí llegó a tener reflejo en la creación de Academias nacionales. La primera academia de Hispanoamérica fue la colombiana, fundada en 1871 (cinco años después del discurso de Sotomayor), y Chile llegaría a tener la propia en 1885. Sotomayor, por supuesto, fue uno de los miembros fundadores de la Academia Chilena de la Lengua. Es claro que la fundación de estas academias, al menos fuera de Chile, no se debe directamente a la intervención de Sotomayor, pero las palabras de nuestro autor son síntoma de una idea que probablemente estuvo rondando entre los unionistas durante esta época. El modelo concreto que tuvieron estas academias para su constitución fue la Real Academia Española, cuya coparticipación en la planificación lingüística hispanoamericana nunca dejó de ser vista como necesaria: recuérdese que Sotomayor concibe el "diccionario hispanoamericano” como un complemento del diccionario de la RAE.

El modelo cultural acerca de la lengua que manifiesta nuestro autor corresponde a la imagen racionalista de raigambre occidental, muy similar a la que han observado Niedzielski y Preston (2002) en la actualidad en el mundo anglosajón y que puede observarse en gran parte de las culturas modernas de origen europeo (Milroy 2001). 
El proceder ideológico de este modelo básicamente consiste en reificar la lengua y convertirla en un objeto mental existente más allá del uso real de los hablantes. Este objeto mental es erigido en modelo, en estándar de las conductas lingüísticas: si una conducta se ajusta a este modelo, es considerado "correcto", “apropiado", etc., y si se aparta de él, lo contrario. Es decir, se introduce una jerarquización valorativa entre las diversas formas observables en el uso, donde solo una de las variantes coexistentes llega a ser considerada la "correcta". De esta manera, se configura un modelo homogéneo, funcionalmente ideal para su utilización en un organismo político-social imaginado también como internamente homogéneo (por ejemplo, una nación-Estado). Para Sotomayor, el acercamiento a esa forma modélica e ideal pasa por el descubrimiento y aplicación de los principios generales que reflejan el "genio" del idioma. Un ejemplo concreto de esta manera de pensar sobre el lenguaje se encuentra en su afirmación de que existe un "sentido jenuino" para cada unidad léxica, cuya fijación le corresponde realizar al diccionario. Normalmente, la creencia en un sentido genuino único para cada palabra va aparejada con una actitud negativa hacia la polisemia, pues se piensa que la existencia de más de una interpretación puede llevar a dificultades en la comunicación (Trudgill 1998). El mismo Andrés Bello había expresado, en un pasaje del prólogo de su Gramática citado por Sotomayor, que uno de los principales “vicios” idiomáticos era "prestar acepciones nuevas a las palabras y frases conocidas, multiplicando las anfibolojías de que por la variedad de significados de cada palabra adolecen mas o ménos las lenguas todas” (Bello 1847: xi). La visión negativa de la polisemia es congruente con la ideología de la lengua estándar, en la medida en que la supresión de la polisemia es un caso específico de reducción de variación, proceso característico de los procesos de estandarización (Milroy y Milroy 1999: 22).

\section{CONCLUSIONES}

Las ideas lingüísticas de Sotomayor dibujan una visión del lenguaje inspirada, en varios aspectos, en el modelo racionalista de la estandarización (Geeraerts 2006 [2003]) y en la ideología de la lengua estándar (Milroy 2001). Esto se manifiesta, por ejemplo, en el rol instrumental que Sotomayor asigna al lenguaje en el progreso de las naciones, en la importancia atribuida al orden y la uniformización y, por último, en la reificación de la lengua, considerada como un ente ideal, existente bajo la forma de principios abstractos y más allá del mero uso. Sin embargo, como hemos apuntado, su ideología lingüística se encuentra también influida por algunas de sus ideas políticas particulares, como la importancia de la autoridad (corporeizada en una academia literaria y científica) y la necesidad de adecuar los principios generales de planificación a la necesidad particular de cada nación. Para Sotomayor, el diccionario, en términos de los procesos estandarizadores, es un instrumento principal de selección y codificación léxica y, en consecuencia, una herramienta concreta que sirve para introducir orden en el uso y fijar la forma ideal de la lengua. En estas ideas, Sotomayor es fiel seguidor del ideario defendido por Andrés Bello durante las décadas fundacionales del pensamiento lingüístico en el Chile independiente.

Cabe destacar, por otra parte, que Sotomayor, a diferencia de autores coterráneos de la época (como Rodríguez 1979[1875]), no manifiesta una actitud intrínsecamente negativa hacia el habla regional. Su rechazo se encuentra dirigido más bien al uso no regido por el orden, a la innovación lingüística caótica debida al desconocimiento de 
la tradición. En sus valoraciones lingüísticas no predomina el eje geolectal (España/ Chile o España/América) sino el eje cultural (cultos/incultos), de manera que los chilenos también pueden considerarse "buenos hablantes” de español en la medida en que se hagan partícipes de la tradición mediante la inmersión en la cultura literaria hispánica. Su actitud crítica hacia el trabajo de la RAE da cuenta, igualmente, de una postura no ciegamente servil hacia todo lo emanado desde la antigua metrópoli. Sotomayor concede importancia de la unidad idiomática y la tradición compartida con España, pero no parece darle mayor jerarquía o un rol de liderazgo a esta nación europea dentro del mundo hispanohablante.

En conclusión, la visión de Sotomayor acerca del rol del diccionario en la estandarización lingüística en Hispanoamérica forma parte de una ideología lingüística congruente con las ideas de mayor aceptación entre los intelectuales chilenos de la época, y al mismo tiempo coherente con su propio ideario político de carácter conservador. Nos atrevemos a señalar que sus ideas acerca del diccionario pudieron haber servido de inspiración para la producción lexicográfica chilena que comenzó a crecer en 1875, pero esto es materia de estudios futuros.

\section{OBRAS CITADAS}

Andersen, Henning. 2009. "Living norms”. Poets to Padonki: Linguistic Authority \& Norm Negotiation in Modern Russian Culture. Eds. Ingunn Lunde y Martin Paulsen. Bergen: Universidad de Bergen. 18-33.

Araneda, Fidel. 1930. "Discurso pronunciado por Don Fidel Araneda Bravo en la sesión solemne celebrada en homenaje a Don Ramón Sotomayor Valdés el 30 de Abril de 1930, día de su centenario”. Anales de la U niversidad de Chile 7, abr.-jun, s. 2: 654-671.

Bello, Andrés. 1847. Prólogo. Gramática de la lengua castellana destinada al uso de los americanos. Santiago, Chile: Imprenta del Progreso. v-xiii.

Blommaert, Jan, ed. 1999. Language Ideological Debates. Berlín/Nueva York: Mouton de Gruyter.

Brahm, Enrique. 1992. "La crisis del conservantismo chileno en la segunda mitad del siglo XIX. Política, gobierno y régimen de gobierno en el itinerario intelectual de don Ramón Sotomayor Valdés”. R evista C hilena de D erecho 19,1:7-33.

Del Valle, José y Luis Gabriel-Stheeman, eds. 2004. La batalla del idioma: Ia intelectualidad hispánica ante la lengua. Madrid/Frankfurt: Iberoamericana/Vervuert.

Deumert, Ana y Wim Vandenbussche. 2003. "Research directions in the history of language standardization”. Germanic Standardizations: Past to P resent. Eds. Ana Deumert y Wim Vandenbussche. Ámsterdam: John Benjamins. 455-469.

Galdames, Luis. 1930. “Ramón Sotomayor Valdés”. Anales de la U niversidad de C hile, año 7, oct.-dic., serie 2:1565-1626.

Gallardo, Andrés. 1978. "Hacia una teoría del idioma estándar”. RLA 16:85-119.

Geeraerts, Dirk. 2006 [2003]. Cultural models of linguistic standardization. Words and other wonders. Papers on lexical and semantic topics. Berlín/Nueva York: Mouton de Gruyter. 272-306.

Haensch, Günther. 2000. Introducción. Textos clásicos para la historia de la lexicografía del español en América [CDROM]. Versión 1.1. Madrid: Fundación Histórica Tavera / Fundación MAPFRE.

Haugen, Einar. 1966. “Dialect, language, nation”. American Anthropologist 68(4):922-935.

Kroskrity, Paul V. 2010. Language ideologies - Evolving perspectives. Society and Language U se. Eds. Jürgen Jaspers, Jan-Ola Östman y Jef Verschueren. Ámsterdam/Filadelfia: John Benjamins. 192-211. 
Lara, Luis Fernando. 2009. "Por una reconstrucción de la idea de la lengua española. Más allá de las fronteras instituidas.” Lengua histórica y normatividad, $2^{\mathrm{a}}$ ed. corr. y aum. México, D. F.: El Colegio de México. 157-193.

Lauria, Daniela. 2011. "Apuntes para una historia de la producción lexicográfica monolingüe en la Argentina: etapas del proceso de diccionarización y modalidades diccionarísticas entre 1870 y 1910”. Boletín de F ilología XLVI,1:106-150.

Lillo, Samuel. 1929. "Discurso de incorporación a la Academia Chilena”. Anales de la U niversidad de Chile, año 7, abr.-jun., serie 2:535-581.

Matus, Alfredo. 1994. "Períodos en la lexicografía diferencial del español de Chile.” Actas del X Congreso de la Asociación de Academias de la Lengua Española. Madrid: Real Academia Española / Espasa Calpe. 189-199.

Matus, Alfredo, Soledad Dargham y José Luis Samaniego. 1992. "Notas para una historia del español en Chile”. H istoria y presente del español de América. Coord. César Hernández. Valladolid: Junta de Castilla y León / PABECAL. 543-564.

Milroy, James. 2001. "Language ideologies and the consequences of standardization". J ournal of Sociolinguistics 5,4:530-555.

Milroy, James y Leslie Milroy. 1999. Authority in Language: Investigating Standard English. Londres: Routledge.

Moré, Belford. 2004. "La construcción ideológica de una base empírica: selección y elaboración en la gramática de Andrés Bello”. La batalla del idioma: Ia intelectualidad hispánica ante la lengua. Eds. José del Valle y Luis Gabriel-Stheeman. Madrid/Frankfurt: Iberoamericana/Vervuert. 67-92.

Niedzielski, Nancy y Dennis Preston. 2003. “F olk Linguistics.” Berlín/Nueva York: Mouton de Gruyter.

Paveau, Marie-Ann. 2011. "Do non-linguists practice linguistics? An anti-eliminative approach to folk theories”. AILA Review 24:40-54.

Pinilla, Norberto. 1945. La controversia filológica de 1842. Santiago: Universidad de Chile.

Quesada, Miguel Ángel. 2002. “El español de América: historia de un concepto.” El español de América, $2^{a}$ ed. Cártago: Editorial Tecnológica de Costa Rica. 15-39.

Rabanales, Ambrosio. 2004-2005. "Temática de las obras lexicográficas chilenas y estudios afines. Una visión panorámica”. Boletín de F ilología XL:137-166.

Rodríguez, Zorobabel. 1979 [1875]. Diccionario de chilenismos. Ed. facsimilar. Valparaíso: Editorial Universitaria de Valparaíso.

Rojas, Darío. 2010. “Estandarización lingüística y pragmática del diccionario: forma y función de los ‘diccionarios de provincialismos’ chilenos”. Boletín de F ilología XLV.1:209-233.

Sotomayor, Ramón. 1866. “Formación del Diccionario hispano-americano. Discurso leído por don Ramón Sotomayor Valdés en el acto de incorporarse en la Facultad de Filosofía y Humanidades de la Universidad el 27 de octubre de 1866”. Anales de la U niversidad de Chile XXVIII.10:665-681.

Trudgill, Peter. 1998. "The Meaning of Words Should Not be Allowed to Vary or Change". Language M yths. Eds. Laurie Bauer y Peter Trudgill. Londres: Penguin. 1-8.

Velleman, Barry L. 2004. “Antiacademicismo lingüístico y comunidad hispánica: Sarmiento y Unamuno”. La batalla del idioma: la intelectualidad hispánica ante la lengua. Eds. José del Valle y Luis Gabriel-Stheeman. Madrid/Frankfurt: Iberoamericana/Vervuert. 35-65.

Wilton, Antje y Martin Stegu. 2011. "Bringing the 'folk' into applied linguistics: An Introduction". AILA Review 24:1-14.

Wilton, Antje y Holger Wochele. 2011. "Linking past and present. A view of historical comments about language”. AILA Review 24:55-67.

Woolard, Kathryn A. 1998. "Introduction: Language Ideology as a Field of Inquiry". Language Ideologies. Practice and Theory. Eds. Bambi B. Schieffelin, Kathryn A. Woolard y Paul V. Kroskrity. Oxford: Oxford University Press. 3-47. 